\title{
The influence of physical and technological magnetron sputtering modes on the structure and optical properties of $\mathrm{CdS}$ and CdTe films
}

\author{
G.S. Khrypunov, G.I. Kopach, M.M. Harchenko, A.I. Dobrozhan \\ National Technical University "Kharkiv Polytechnic Institute" \\ 21, Kirpichov str., 61002 Kharkiv, Ukraine \\ E-mail: gkopach@ukr.net
}

\begin{abstract}
To create technology for preparation of CdS and CdTe thin films by direct current magnetron sputtering, the influence of physical and technological condensation modes on the crystal structure and optical properties of these films were investigated. The laboratory method of DC magnetron sputtering with preheating of the target for the mentioned films on glass substrates was developed. We obtained the CdS layers with hexagonal structure $150 \ldots 200 \mathrm{~nm}$ thick under conditions when the plasma discharge current density was $1.1 \mathrm{~mA} / \mathrm{cm}^{2}$ and the deposition rate $-30 \ldots 40 \mathrm{~nm} / \mathrm{min}$. The bandgap in the obtained CdS films is $E_{g}=2.38 \ldots 2.41 \mathrm{eV}$. After annealing in vacuum, the optical transparence of CdS films reaches $80 \ldots 90 \%$, which allows to use these films as a transparent window layer in solar cells based on heterojunctions of $\mathrm{CdS} / \mathrm{CdTe}$. When the plasma discharge current density is $2.2 \ldots 5.4 \mathrm{~mA} / \mathrm{cm}^{2}$ and the deposition rate is $200 \mathrm{~nm} / \mathrm{min}$, we obtained CdTe layers with hexagonal structure up to $5 \mu \mathrm{m}$ thick. The transmittance of CdTe films with hexagonal structure in the wavelength range of the visible spectrum is up to $5 \%$, and in the infrared spectral range is about $60 \%$. The bandgap in the obtained CdTe layers of different thickness is $1.52 \ldots 1.54 \mathrm{eV}$. After chloride treatment as a result of the phase transition wurtzite-sphalerite, the investigated CdTe films contain only the stable cubic structure and can be used as a base layer of solar cells.
\end{abstract}

Keywords: cadmium telluride, cadmium sulfide, direct current magnetron sputtering, thin films.

Manuscript received 10.02.17; revised version received 18.04.17; accepted for publication 14.06.17; published online 18.07.17.

\section{Introduction}

Thin-film solar cells based on cadmium sulfide $(\mathrm{CdS}) /$ cadmium telluride (CdTe) heterojunction are prospective for industrial production [1-3]. In heterosystems $n$-CdS $/ p$-CdTe, the CdS layer is used as the window one. It allows to reduce a negative impact of surface recombination of non-equilibrium charge carriers by removing their active generation area from the illuminated surface. One of the economical and high-tech methods for thin films is magnetron sputtering [4]. Implementation of the radio-frequency magnetron sputtering regime for $\mathrm{CdS}$ and $\mathrm{CdTe}$ films allows to prevent accumulation of the excess electric charge on the surface of the target. But this method is expensive, energy intensive and requires a special technological equipment. Ukrainian electronic industry mastered the high-tech and economical method of direct current magnetron sputtering (DC magnetron sputtering) of materials. However, there are some technological problems during deposition of semiconductor films by this method. They are caused by low conductivity of CdS and CdTe pressed powder targets and sufficiently low emission ability of these materials. Therefore, the development of DC magnetron sputtering of semiconductors and the study of crystal structure and optical properties of CdS and CdTe films grown under 
different physical and technological modes of condensation are relevant.

\section{Experiments}

In laboratory technology for condensation of $\mathrm{CdS}$ and CdTe films by using DC magnetron sputtering, it was used the design of VUP-5m magnetron, which feature was that the cooling circuit covered only the magnetic system with the result that there was no forced cooling of the sputtered semiconductor pressed powder target. To implement the process of thermionic emission of electrons from the target material for plasma discharge ignition, the target was preheated for $10 \ldots 15 \mathrm{~min}$.

$\mathrm{CdS}$ films were condensed on soda-lime glass substrates at different physical and technological modes: substrate temperature $T_{\text {sub }}=120 \ldots 200^{\circ} \mathrm{C}$, pressure of inert gas $P_{\mathrm{Ar}}=0.9 \ldots 1 \mathrm{~Pa}$, magnetron discharge current density $J=1.1 \mathrm{~mA} / \mathrm{cm}^{2}$, the voltage on magnetron $V=550 \ldots 600 \mathrm{~V}$, deposition time $5 \mathrm{~min}$. When manufacturing $\mathrm{CdS} / \mathrm{CdTe}$ based solar cells, the base CdTe layer is condensed on CdS layer at $T_{s u b}>300{ }^{\circ} \mathrm{C}$. The effect of annealing in vacuum $10^{-4} \mathrm{~Pa}$ at $400 \ldots 420^{\circ} \mathrm{C}$ for $30 \mathrm{~min}$ on the structure and optical properties of $\mathrm{CdS}$ layers was investigated.

CdTe layers were also obtained on soda-lime glass substrates under the following conditions: $T_{s u b}=$ $295 \ldots 315{ }^{\circ} \mathrm{C}, P_{\mathrm{Ar}}=0.8 \ldots 1 \mathrm{~Pa}, J=2.2 \ldots 5.6 \mathrm{~mA} / \mathrm{cm}^{2}$, $V=600 \ldots 650 \mathrm{~V}$, deposition time $15 \ldots 25 \mathrm{~min}$. To determine the effect of heat treatment on the structure of CdTe samples, the CdTe layers annealing was carried out in vacuum at $T=400{ }^{\circ} \mathrm{C}$ for $20 \mathrm{~min}$.

To use the obtained CdTe films as base layers of solar cells, there was performed chloride treatment $(\mathrm{Cl}$ treatment) in vacuum $P=5.3 \cdot 10^{-3} \mathrm{~Pa}$ and temperature of $\mathrm{CdCl}_{2}$ evaporator $470 \ldots 475^{\circ} \mathrm{C}$ for $5 \mathrm{~min}$ with subsequent annealing in air at $T=430{ }^{\circ} \mathrm{C}$ for $25 \mathrm{~min}$ [5].

The structure of the obtained CdTe and cadmium sulfide films was studied using the X-ray diffractometry (XRD) methods [6]. There was performed automatic recording of X-ray spectra at $\theta-2 \theta$ scanning by using $X$ ray diffractometer DRON-4 with the step $0.01 \ldots 0.02$ degrees in $\mathrm{K}_{\alpha}$-radiation of cobalt anode.

To accurately determine the phase composition of the obtained CdTe films, we used the "oblique" shooting method, during which in the radiation of cobalt anode in the process of $\theta-2 \theta$ scanning performed were detection and registration of diffraction reflections from those sphalerite and wurtzite planes that are not detected in the foregoing registration method because of texturing of samples.

The CdTe cubic structure lattice parameter was determined using the formula:

$$
a=d \sqrt{h^{2}+k^{2}+l^{2}},
$$

where $d$ is the interplanar spacing.
For precise determination of the lattice parameter, the Nelson-Rhyl extrapolation method was used.

Optical studies of CdTe and CdS layers were carried out using the spectrometer SF-2000. The transmission spectrum of studied films was used to determine the thickness of the layers according to [7]. The thickness of the layers was determined using the formula:

$$
t=\frac{M \cdot \lambda_{1} \cdot \lambda_{2}}{2\left(n\left(\lambda_{1}\right) \cdot \lambda_{2}-n\left(\lambda_{2}\right) \cdot \lambda_{1}\right)},
$$

where $\lambda_{1}, \lambda_{2}$ are the wavelengths of two adjacent extremums (interferential maxima or minima of transmission spectrum) in nm; $n\left(\lambda_{1}\right), n\left(\lambda_{2}\right)$ - refractive index, depending on the wavelengths $\lambda_{1}, \lambda_{2}$.

The bandgap of thin films was determined by calculating the dependence of absorption coefficient on the wavelength $\alpha(\lambda)$ using [8]:

$T=(1-R) \cdot e^{-\alpha \cdot t}$,

where $T$ is the transmission coefficient; $R$ - reflection coefficient; $t$ - film thickness.

The bandgaps of CdTe and CdS polycrystalline films were determined by extrapolation of the linear portion of the $(\alpha \cdot h v)^{2}=f(h v)$ curves (where $h-$ Planck constant, $v$ - frequency) to the intersection with the $h v$ energy axis.

\section{Results and discussion}

When studying the XRD patterns of the lattice of CdS layers grown at different substrate temperatures $T_{\text {sub }}=$ $120 \ldots 200^{\circ} \mathrm{C}$ (Fig. 1), the only one diffraction peak was observed for all of the received films at the angle $2 \theta=30.62^{\circ}$. This peak corresponds to reflection (111) of cubic structure or (002) hexagonal phase of CdS. A low intensity of this peak is caused by a small thickness of the sample. It does not allow to accurately determine the phase composition of the CdS samples using the XRD methods.

But considering that the $\mathrm{CdS}$ stable structure is hexagonal [9], subsequent diffractogram data processing (Table 1) was done for this CdS phase. For all the samples, the intensity of peak lies in the $220-280 \mathrm{imp} / \mathrm{s}$ range, which indicates almost the same thickness of obtained CdS layers. The estimated values of interplanar spacing lie in the $3.379 . .3 .391 \AA$ range, which corresponds to the value of lattice parameter $c=$ $6.758 \ldots 6.782 \AA$. The obtained values of the parameter $c$ are bigger than the table value for single crystals $(c=$ $6.7198 \AA$, PCPDFWIN\# 411049) and indicate the presence of macrostresses. The full width at half maximum (FWHM) of the peaks in the $0.3 \ldots 0.38$ degree range on the $2 \theta$ scale are typical for $\mathrm{CdS}$ thin layers obtained using vacuum methods [10] and caused by small grain sizes of the film. 

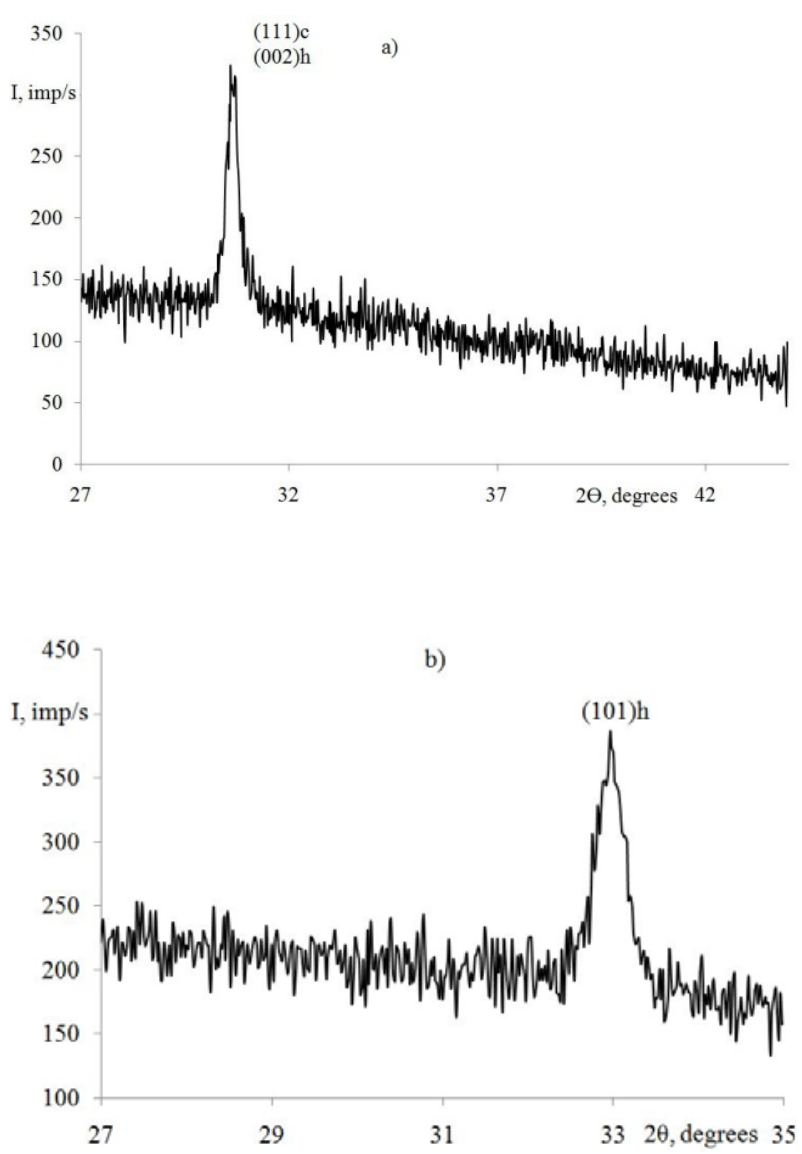

Fig. 1. XRD patterns of the obtained CdS sample layer (a) and after its annealing (b).
Spectral dependences of transmission coefficient for the obtained CdS layers are presented in Fig. 2. According to results of optical studies there is a strong absorption of radiation in the wavelength range 400 to $500 \mathrm{~nm}$, while in the infrared spectral range the CdS films transparence is up to $80 \%$. The typical thickness of investigated $\mathrm{CdS}$ layers is $150 \ldots 200 \mathrm{~nm}$. The bandgap in the prepared CdS films is $E_{g}=2.38 \ldots 2.41 \mathrm{eV}$, which is close ( $E_{g}=$ $2.42 \ldots 2.45 \mathrm{eV}$ ) to that of $\mathrm{CdS}$ single crystals.

After annealing of $\mathrm{CdS}$ layers in vacuum, in the XRD pattern (Fig. 1b) only one intense peak was detected at the angle $2 \theta=32.8^{\circ}$, which corresponds to reflection (101) of stable $\mathrm{CdS}$ hexagonal phase. The optical transparence of CdS films is up to $90 \%$ over the entire spectral range, which indicates the ability to use these films as a transparent window layer in solar cells based on heterostructure of $\mathrm{CdS} / \mathrm{CdTe}[10]$.

We investigated the structure and optical properties of CdTe thin films grown on glass substrates using DC magnetron sputtering method at different physical and technological condensation modes (Table 2).

The typical XRD patterns of CdTe sample layers obtained at different physical and technological condensation modes (samples 3, 4, 6, 7) are shown in Fig. 3 (by the example of sample 6).

In all diffractograms of the studied CdTe films, there are two distinct peaks at the angles $2 \theta 27.05^{\circ}$ and $91.05^{\circ}$. According to the table ASTM 15-0770, they can belong both to hexagonal and cubic structures of CdTe: wurtzite reflections (002) and (006) and sphalerite reflections (111) and (333), respectively. Also, the reflections (103) and (105) of hexagonal phase CdTe are observed in diffractograms.

Table 1. CdS films diffractograms processing results.

\begin{tabular}{|c|c|c|c|c|c|}
\hline Sample № & $T_{\text {sub }},{ }^{\circ} \mathrm{C}$ & Peak position, degrees & Interplanar spacing, $\AA$ & Intensity, imp/s & FWHM, degrees \\
\hline 2 & 120 & 30.62 & 3.388 & 216 & 0.33 \\
\hline 3 & 130 & 30.59 & 3.391 & 280 & 0.33 \\
\hline 1 & 150 & 30.58 & 3.391 & 44 & 0.38 \\
\hline 4 & 175 & 30.63 & 3.386 & 260 & 0.30 \\
\hline 6 & 180 & 30.64 & 3.385 & 269 & 0.34 \\
\hline 5 & 200 & 30.70 & 3.379 & 234 & 0.30 \\
\hline
\end{tabular}

Table 2. Technological modes of obtaining CdTe films.

\begin{tabular}{|c|c|c|c|c|c|c|}
\hline № & $T_{\text {sub }}$ at start, C & $T_{\text {sub }}$ at finish, C & $t, \min$ & $P_{\mathrm{Ar}}, \mathrm{Pa}$ & $U, \mathrm{~V}$ & $I, \mathrm{~mA}$ \\
\hline 1 & 330 & 315 & 15 & $0.8-1$ & 600 & 60 \\
\hline 2 & 300 & 300 & 15 & $0.8-1$ & 600 & 40 \\
\hline 3 & 295 & 292 & 25 & $0.8-1$ & 600 & 40 \\
\hline 4 & 300 & 300 & 25 & $0.8-1$ & 600 & 60 \\
\hline 5 & 270 & 315 & 15 & $0.9-1$ & 600 & 80 \\
\hline 6 & 312 & 295 & 25 & $0.9-1$ & 650 & 80 \\
\hline 7 & 312 & 297 & 25 & $0.8-0.9$ & 650 & 100 \\
\hline 8 & 300 & 316 & 25 & $0.9-1$ & 600 & 80 \\
\hline 9 & 300 & 313 & $0.9-1$ & 600 & 80 \\
\hline
\end{tabular}




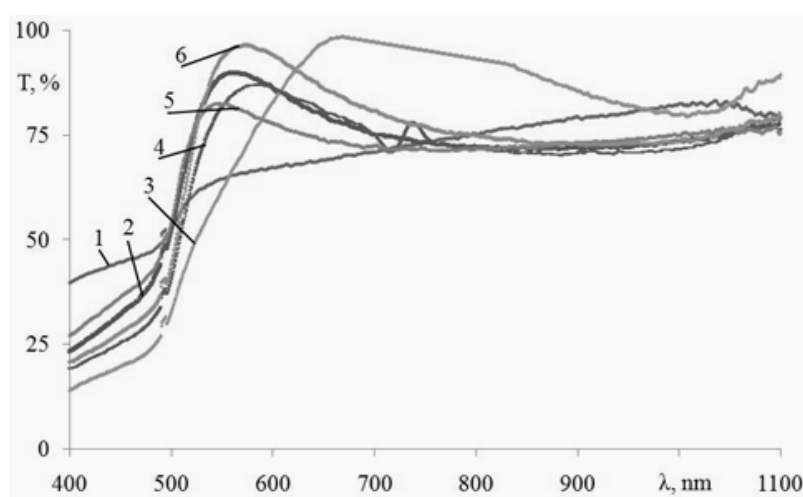

Fig. 2. Spectral dependences of the transmission coefficient for the samples 1 to 6 , respectively.

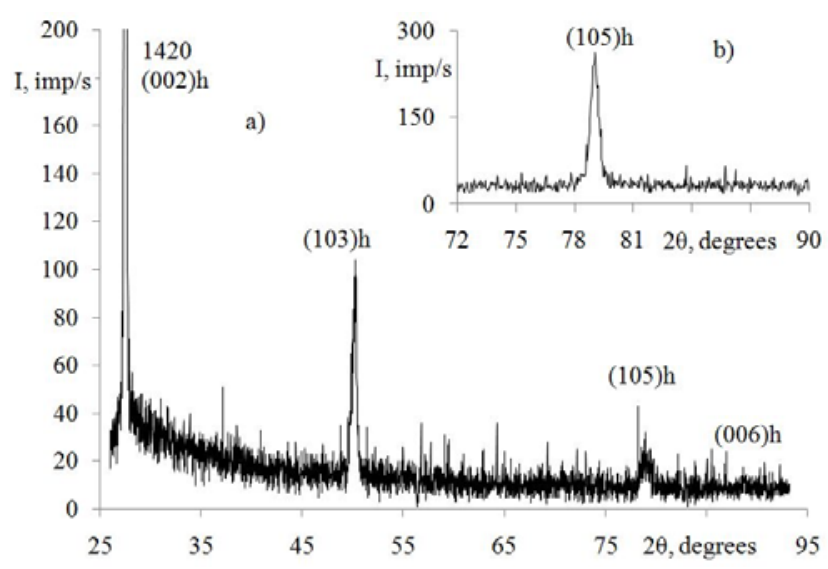

Fig. 3. Typical XRD patterns of the obtained CdTe films: (a) sample 6, (b) sample 6, by using the "oblique" shooting method.

Using the "oblique" shooting method of diffractometry at the angles $2 \theta 72^{\circ}$ to $85^{\circ}$ allowed determining the exact phase composition of grown $\mathrm{CdTe}$ layers when rotating the sample by the angle $20.5^{\circ}$. In all diffractograms, only the reflection (105) of hexagonal phase was observed (Fig. 3b). Thus, all the studied CdTe films obtained in different physical and technological condensation modes by DC magnetron sputtering method contain only metastable hexagonal structure. The annealing of samples in vacuum at $T=400{ }^{\circ} \mathrm{C}$ for 20 min does not change the CdTe layers phase.

Traditional $\mathrm{Cl}$ treatment of the studied CdTe films facilitates phase transition wurtzite-sphalerite, what can be seen in XRD patterns. The typical diffractogram of the sample 8 (Table 2) is shown in Figs. $4 \mathrm{a}$ and $4 \mathrm{~b}$.

All peaks that belong to the stable cubic structure CdTe are observed. Using the "oblique" shooting method at the angles $2 \theta 72.5 \ldots 87.5^{\circ}$, when rotating the sample by the angle $20.5^{\circ}$, it was found that, in this area of XRD pattern, only cubic structure peaks (331) and (422) can be observed, hexagonal structure peaks (105) are not presented. Thus, $\mathrm{Cl}$ treatment facilitates phase transition wurtzite-sphalerite, thereby studied CdTe films contain only stable cubic structure.

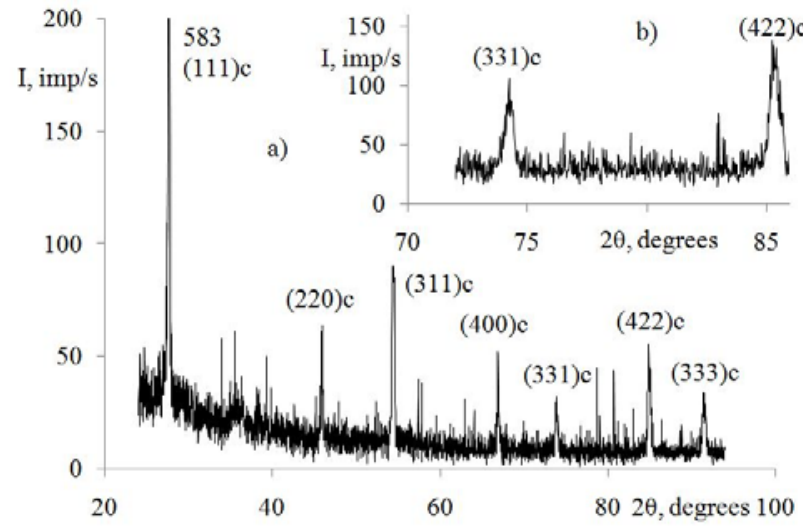

Fig. 4. XRD pattern of the sample 8: (a) after $\mathrm{Cl}$ treatment and annealing in air and (b) by using the "oblique" shooting method.

After $\mathrm{Cl}$ treatment, we observed a slight decrease of FWHM values of peaks (111) and (333) as compared with the peaks (002) and (006) of hexagonal phase in the samples before $\mathrm{Cl}$ treatment and annealing in air (Figs. 1 and 4). This indicates the passing of the recrystallization process and grain size increasing in the polycrystalline CdTe films. The calculated value of lattice parameter in the cubic structure of CdTe films after $\mathrm{Cl}$ treatment is $a=6.4905 \AA$. The deviation from the value $a$ in the table ASTM 15-0770 is less than $0.2 \%$.

Spectral dependences of the transmission coefficient for CdTe film samples 1-9 are shown in Fig. 5 (Table 2).

For all the samples, there is a strong absorption of radiation within the wavelength range $400 \ldots 700 \mathrm{~nm}$ and sharp fall at the band edge within the range $750 \ldots 800 \mathrm{~nm}$. In the infrared spectral range, the transparence of films 4 and 5 is about $65 \%$, films 2 and 3 is about $50 \%$, films $1,6,8$ and 9 is about $30 \%$.

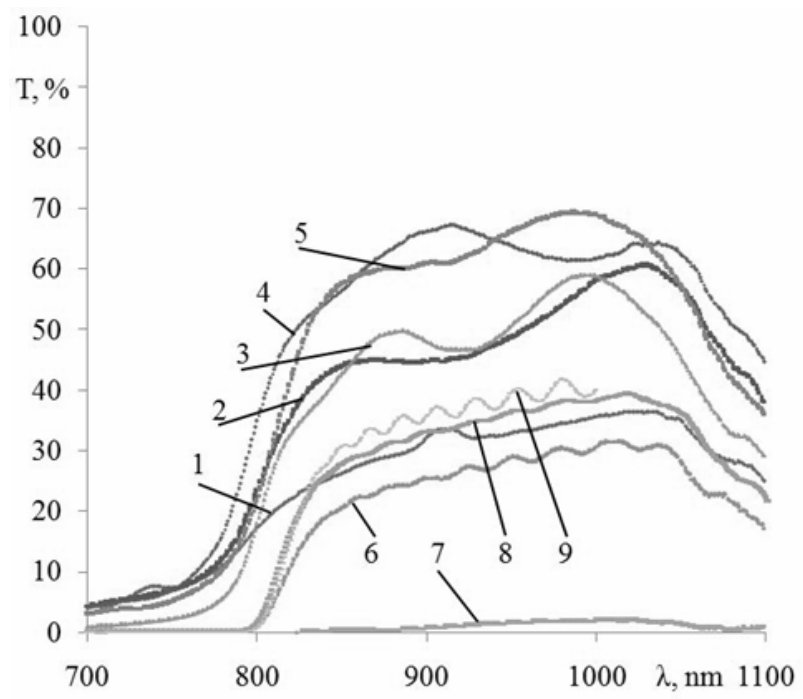

Fig. 5. Spectral dependences of the transmission coefficient for the samples 1 to 9 . 
Table 3. The value of the bandgap for CdTe films of different thicknesses.

\begin{tabular}{|c|c|c|c|c|c|}
\hline № & $t, \min$ & $I, \mathrm{~mA}$ & $T, \mathrm{C}$ & Film thickness, $\mathrm{nm}$ & $E_{g}, \mathrm{eV}$ \\
\hline 1 & 15 & 60 & 315 & 300 & 1.51 \\
\hline 2 & 15 & 40 & 300 & 390 & 1.53 \\
\hline 3 & 25 & 40 & 292 & 1030 & 1.51 \\
\hline 4 & 25 & 60 & 300 & 2360 & 1.5 \\
\hline 5 & 15 & 80 & 315 & 2120 & 1.52 \\
\hline 6 & 25 & 80 & 300 & 5200 & 1.52 \\
\hline 7 & 15 & 100 & 297 & 5500 & - \\
\hline 8 & 25 & 80 & 316 & 4900 & 1.54 \\
\hline 9 & 25 & 80 & 312 & 5000 & 1.53 \\
\hline
\end{tabular}

The obtained results for the film thickness and bandgap based on optical researches are presented in Table 3 .

Being based on the calculated values of the CdTe film thickness that differs by the condensation time, the condensation rate that depends on the plasma discharge current was calculated (Fig. 6).

The average deposition rate of CdTe films increases with increasing the plasma discharge current regardless of the condensation time. Increasing the slope of the plot areas at a discharge current higher than $60 \mathrm{~mA}$ indicates that the chosen magnetron operation mode provides sufficiently high increasing the film deposition rate. The fact, that when the condensation time is $25 \mathrm{~min}$, the average deposition rate of film is higher than in the case $t=15 \mathrm{~min}$, is caused by the simultaneous occurrence of two processes: target sputtering and increasing its material sublimation rate with an increase of its temperature due to $\mathrm{Ar}$ ions bombing. When the plasma discharge current was $>80 \mathrm{~mA}$, it was got the high enough rate of condensation reaching the level $150 \ldots 200 \mathrm{~nm} / \mathrm{min}$. At identical operating parameters of the magnetron and Ar pressure in vacuum chambers, the relative difference of $\mathrm{CdTe}$ films thickness is lower than $2 \%$ (Table 1 , samples 6,8 and 9).

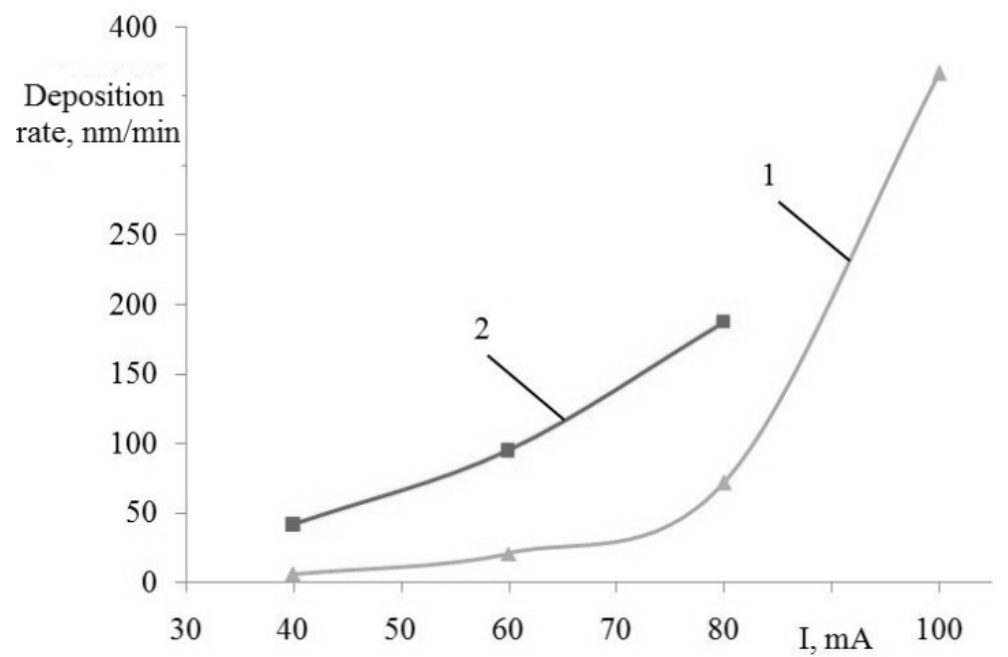

Fig. 6. Dependence of the average CdTe film deposition rate on the discharge current in the mentioned modes for condensation time 15 (1) and 25 (2) minutes. 


\section{Conclusions}

The laboratory method of DC magnetron sputtering with preheating of the target for $\mathrm{CdS}$ and CdTe films on sodalime glass substrates was developed. The $\mathrm{CdS}$ layers with hexagonal modification $150 \ldots 200 \mathrm{~nm}$ thick under conditions when the plasma discharge current density is $1.1 \mathrm{~mA} / \mathrm{cm}^{2}$. The deposition rate $30 \ldots 40 \mathrm{~nm} / \mathrm{min}$ was obtained. The bandgap in these $\mathrm{CdS}$ films is $E_{g}=$ $2.38 \ldots 2.41 \mathrm{eV}$. After annealing in vacuum, the optical transparence of $\mathrm{CdS}$ films is $80 \ldots 90 \%$, which allows to use these films as a transparent window layer in solar cells based on the heterostructure $\mathrm{CdS} / \mathrm{CdTe}$.

When the plasma discharge current density is $2.2 \ldots .5 .4 \mathrm{~mA} / \mathrm{cm}^{2}$ and the deposition rate is $200 \mathrm{~nm} / \mathrm{min}$, CdTe layers with hexagonal structure up to $5 \mu \mathrm{m}$ thick were obtained. The transmittance of CdTe films with the hexagonal structure in the wavelength range of the visible spectrum is up to $5 \%$, and in the infrared spectral range is about $60 \%$. The bandgap in the obtained CdTe layers of different thickness is $1.52 \ldots 1.54 \mathrm{eV}$.

After $\mathrm{Cl}$ treatment with subsequent annealing in air at $T=430 \mathrm{C}$ for $25 \mathrm{~min}$, as a result of the phase transition wurtzite-sphalerite, the investigated CdTe films contain only the stable cubic structure, which value of the lattice parameter is $a=6.4905 \AA$, which by less than $0.2 \%$ deviates from the tabular value. These CdTe films can be used as a base layer of $\mathrm{CdS} / \mathrm{CdTe}$ based solar cells.

\section{References}

1. Bosio A., Romeo N., Mazzamuto S., Canevari V. Polycrystalline CdTe thin films for photovoltaic applications. Prog. Cryst. Growth Charact. Mater. 2006. 52, No. 4. P. 247-279.
2. Hädrich M., Heisler C., Reislöhner U., Kraft C., Metzner H. Back contact formation in thin cadmium telluride solar cells. Thin Solid Films. 2011. 519, No. 21. P. 7156-7159.

3. Wu X. High-efficiency polycrystalline CdTe thinfilm solar cells. Solar Energy. 2004. 96. P. 803814.

4. Li H., Liu X. Improved performance of CdTe solar cells with CdS treatment. Solar Energy. 2015. 115. P. 603-612.

5. Kharchenko N.M., Khripunov G.S., Li T.A. Technology optimization of the chloride treatment of cadmium chalcogenide thin films. JPSE. 2008. 6, No. 3-4. P. 128-133.

6. Panchekha P.A., Alaverdova O.G., Gnidash V.I. Heterophase state and polytexture of CdTe films deposited from the ion-molecular beam. Ukr. J. Phys. 2000. 45, No. 1. P. 75-80.

7. Brus V.V., Solovan M.N., Maystruk E.V. et al. Specific features of the optical and electrical properties of polycrystalline CdTe films grown by the thermal evaporation method. Physics of the Solid State. 2014. 56, No. 10. P. 1947-1951.

8. Salem A.M., El-Ghazzawi M.E. Structural and optical properties of chemically deposited $\mathrm{CdCr}_{2} \mathrm{~S}_{4}$ thin films. Semicond. Sci. Technol. 2004. 19. P. 236-241.

9. Aven M. and Prener J.S. Physics and Chemistry of II-VI Compounds. North-Holland \& John Wiley and Sons, Amsterdam \& New York, 1967.

10. Khrypunov G., Romeo A., Kurtzesau F., Batzner D.L., Zoggand H., Tiwari A.N. Recent developments in evaporated CdTe solar cells. Solar Energy Materials \& Solar Cells. 2006. 90, No. 6. P. 664-677. 